\title{
The activation of eco-driving mental models: Can text messages prime drivers to use their existing knowledge and skills?
}

\author{
Sanna M. Pampel ${ }^{1,2} \cdot$ Samantha L. Jamson $^{2} \cdot$ Daryl Hibberd $^{2} \cdot$ Yvonne Barnard $^{2}$
}

Received: 6 June 2017 / Accepted: 16 September 2017 / Published online: 27 September 2017

(C) The Author(s) 2017. This article is an open access publication

\begin{abstract}
Eco-driving campaigns have traditionally assumed that drivers lack the necessary knowledge and skills and that this is something that needs rectifying. Therefore, many support systems have been designed to closely guide drivers and fine-tune their proficiency. However, research suggests that drivers already possess a substantial amount of the necessary knowledge and skills regarding eco-driving. In previous studies, participants used these effectively when they were explicitly asked to drive fuel-efficiently. In contrast, they used their safe driving skills when they were instructed to drive as they would normally. Hence, it is assumed that many drivers choose not to engage purposefully in eco-driving in their everyday lives. The aim of the current study was to investigate the effect of simple, periodic text messages (nine messages in 2 weeks) on drivers' eco- and safe driving performance. It was hypothesised that provision of eco-driving primes and advice would encourage the activation of their eco-driving mental models and that comparable safety primes increase driving safety. For this purpose, a driving simulator experiment was conducted.
\end{abstract}

Sanna M. Pampel

sanna.pampel@nottingham.ac.uk

Samantha L. Jamson

S.L.Jamson@its.leeds.ac.uk

Daryl Hibberd

D.L.hibberd@leeds.ac.uk

Yvonne Barnard

Y.Barnard@leeds.ac.uk

1 Institute for Transport Studies, University of Leeds, University Road 34-40, Leeds LS2 9JT, UK

2 Present Address: Human Factors Research Group, Faculty of Engineering, University of Nottingham, Nottingham NG7 2RD, UK
All participants performed a pre-test drive and were then randomly divided into four groups, which received different interventions. For a period of 2 weeks, one group received text messages with eco-driving primes and another group received safety primes. A third group received advice messages on how to eco-drive. The fourth group were instructed by the experimenter to drive fuel-efficiently, immediately before driving, with no text message intervention. A posttest drive measured behavioural changes in scenarios deemed relevant to eco- and safe driving. The results suggest that the eco-driving prime and advice text messages did not have the desired effect. In comparison, asking drivers to drive fuel-efficiently led to eco-driving behaviours. These outcomes demonstrate the difficulty in changing ingrained habits. Future research is needed to strengthen such messages or activate existing knowledge and skills in other ways, so driver behaviour can be changed in cost-efficient ways.

Keywords Driving simulator $\cdot$ Behavioural change . Priming $\cdot$ Text messages $\cdot$ Eco-driving $\cdot$ Mental models . Fuel efficiency

\section{Introduction}

\subsection{Background}

Eco-driving involves a number of practises drivers can use to reduce their fuel consumption, in order to benefit economically and reduce emissions such as carbon dioxide (Mensing et al. 2014). These practises include vehicle maintenance such as tyre pressure checks and route choice. In addition, changes in the driving style have the potential to reduce fuel consumption by $5-10 \%$ (Barkenbus 2010). Fuel-efficient behaviours include driving in higher gears (Beusen et al. 
2009), maintaining an efficient speed (Mensing et al. 2013, 2014; Samaras and Ntziachristos 1998) by anticipation and coasting, as well as avoiding harsh accelerations (Johansson et al. 1999).

Studies that have tried to encourage eco-driving behaviours to be adopted indicate that simple information provision does not change people's behaviour (Delicado 2012). For instance, Schall et al. (2016) investigated the effects of a theoretical eco-driving training course, which did not change behaviours - even in conjunction with monetary incentives. This shortfall of behaviour change could be explained with the phased timing of the course. It was introduced after the participating drivers had already been subjected to the ecodriving incentives for 6 months. Adding theoretical information to the mix of interventions at a later point in time could have been perceived as patronising, undermining the drivers' sense of competence and control over their driving. However, in a review of driver training, Cloke et al. (1999) concluded that simply training safe and eco-driving might not be effective.

Notably, it would appear that drivers already hold relevant knowledge, for example, regarding gear usage, gentle accelerations and decelerations, which are representative of eco-driving behaviour (Waters and Laker 1980; McIlroy and Stanton 2017). In a previous experiment, reported in Pampel et al. (2015), it was shown that many drivers are able to reduce fuel consumption without being explained how to do so. Other studies have also identified effects that support these findings. For example, an eco-driving support system (EDSS) tested by Birrell and Young (2011) did not advise specifically on speed choice, but participants decreased mean speed and the time spent speeding.

An investigation involving eco-driving training for bus drivers found that behavioural changes occurred not only in the intervention group, but in the control group as well (af Wåhlberg 2007). These involved less acceleration and deceleration, as well as improved speed maintenance, but no reductions in fuel consumption. These effects could have arisen due to confounding variables such as weather. However, all participants were recruited in the same company, which suggests the possibility of influences of the intervention on the control group. Consequently, the control group may have practised eco-drive as well, but according to their own understanding.

Educational information is still crucial for invoking behaviour change (cf. Abrahamse et al. 2005). Enhanced knowledge can eliminate common misconceptions, for instance the belief that eco-driving is necessarily slow driving (Harvey et al. 2013; van der Voort et al. 2001; Waters and Laker 1980). EDSS could generate long-lasting effects by providing regular feedback during driving (Hiraoka et al. 2010), which is able to improve and fine-tune eco-driving proficiency. Their presence and regular messages can also change habits over time (Jackson 2005). However, these systems can be complex and expensive to build, and potentially distracting to use. Visual eco-driving information, for example, can divert the gaze off the road (Engström et al. 2005; Hibberd et al. 2015) and increase workload (van Erp and van Veen 2004). On the other hand, auditory signals could annoy drivers, which was mentioned by participants in a focus group (Meschtscherjakov et al. 2009). In a field trial with a system alerting drivers as they exceeded the speed limit (Adell et al. 2008), a post-study questionnaire revealed that the system was perceived as more "irritating" and "annoying" compared to a haptic feedback gas pedal.

Drivers' own ability to reduce their fuel consumption without intervention points to other possible reasons for the lack of actual eco-driving. Major barriers for environmentally friendly behaviours include a lack of motivation and ingrained habits. Externally rewarding people has been shown to have limited effects, particularly in the long term (Schall et al. 2016). In fact, financial savings of single trips may be too small to encourage behaviour changes (Dogan et al. 2014; Harvey et al. 2013). Dogan et al. (2014) showed that environmental feedback has more potential to motivate drivers to invest the effort in behavioural changes. Disappointingly, this only applies to a minority of drivers. Harvey et al. (2013) organised focus groups and conducted a questionnaire survey in the UK and the Czech Republic, and found that only $20 \%$ of the respondents would be motivated by environmental considerations.

Training courses primarily address awareness and knowledge, but as old habits are not overcome, their effects on fuel consumption wane over time (Beusen et al. 2009; af Wåhlberg 2007). Interestingly, in a former study (Pampel et al. 2015), the participants' "safe" driving behaviour was not statistically significant from their "normal" driving. Hence, it could be the case that their safe driving mental models are more accessible than eco-driving mental models and therefore easier to practise, and that they might take precedence in trade-off situations (cf. Dogan et al. 2011).

It is evident that drivers do not activate their existing eco-driving knowledge and skills to their full potential in everyday and unsupported driving conditions. However, ecodriving is observable in behavioural changes and in fuel savings when drivers are prompted to drive fuel-efficiently. The question arises whether it is possible to use regular messages to encourage the use of existing eco-driving knowledge and skills and thus overcome habits. In past research, repeated messages were effective in changing behaviour sustainably, regarding environmentally friendly behaviours (Seligman et al. 1981) and eco-driving in particular (af Wåhlberg 2007; Siero et al. 1989). Besides messages, there is evidence that drivers could be reminded of specific behaviours in other ways. In a study by Tarkiainen et al. (2014), 39\% of the participants reported that the presence of a support system alone 
led them to drive more safely and economically. It appears that EDSS trains and, in addition, simply reminds drivers to eco-drive. Hence, messages, EDSS and potentially other interventions may not only be changing preconditions such as motivations, attitudes and the ability to eco-drive, but encourage the use of existing knowledge and skills. Investigating the reminding effect can offer further insights into behaviour change and could suggest solutions for more costeffective and less intrusive means. For such research, mental model theory provides a suitable theoretical basis, because it allows isolating the effect of activating and deactivating mental models of different driving styles.

\subsection{The activation of eco-driving mental models}

The theoretical underpinning for understanding drivers' eco-driving knowledge and skills and their activation was based on mental models. Johnson-Laird, the originator of the mental model theory as it is presently understood, referred to such a representation as a schema, "a single representative sample" (1983, p. 264) of a real entity. The idea that humans store representative schemas of the world is central to the understanding in the present study. In essence, it is assumed that humans possess a library of mental models, which comprise many aspects of the world, including objects, situations and events, but also sequences of events and actions (Garnham 1997; Johnson-Laird 1983; Rumelhart 1980).

As people perceive information, a matching mental model is retrieved and fed with the variables of the current situation. Traditional proponents of the mental model theory state that the representations are purely symbolic and abstract, with combinatorial and linguistic properties (e.g. Johnson-Laird 1983; Newell 1973; Putnam 1975). Although it is understood that mental models guide people's perceptions and actions (Johnson-Laird 1983), the driving context requires a strong focus on the actual task. Embodied cognition science is based on the premise that cognitive processing is substantially influenced by the body, with its motor and perceptual systems (Wilson 2002). This understanding of cognition also takes the physical and cultural environment into account (e.g. Carsten and Vanderhaegen 2015; Hutchins 1995). Accordingly, the external environment can affect the formation and operation of mental models. Direct manipulation interfaces, for example, are designed to bypass the higher cognitive levels and guide motion directly (Hutchins et al. 1985; McIlroy and Stanton 2014). Both, the traditional view and embodied cognition have their merits with regard to the driving task. The hierarchical models of Rasmussen (1983) and Michon (1985) acknowledge both in a coherent structure, with the more conscious mental models in the higher levels, and the perceptions and actions at the lower, more subconscious level.
In mental model theory, attitudes refer to a person's relation to the content of mental models (Barwise and Perry 1981). Attitudes are formed with regard to the potential instrumentality of an object, for example, how it supports achieving goals and fulfilling needs. Formation can also occur when taking sides, such as in athletic competitions and dramatic literature (Greenwald 2014). Attitudes can exist and be changed on the more conscious cognitive levels and on the more internalised, automated levels (Gawronski and Bodenhausen 2006). The latter can be changed with implicit cues such as repeated positive or negative stimuli, which change the underlying associative structure, or pattern activation. Change of more explicit attitudes can be achieved with a change in evaluations and propositions, and processes to achieve cognitive consistency. However, attitudes do not necessarily predict behaviours. For instance, a questionnaire about environmentally sustainable behaviours identified a large gap between attitudes and self-reported behaviours (Christie and Jarvis 2001).

The previous study by Pampel et al. (2015) found that many drivers have eco-driving mental models, but also that these were not retrieved and activated during the baseline drives. Instead, safe driving did not significantly differ from "normal" driving behaviour. From this starting point, mental model theory allows studying approaches to behaviour change are different from changing attitudinal, motivational and intentional factors, such as the factors proposed by the Theory of Planned Behaviour (Ajzen 1991). In addition, it was not attempted to change eco-driving mental models or the environment in the car, for example, with feedback systems. The emphasis was on an activation of the existing eco-driving mental models. This can in theory be achieved by various means.

One subtle means to influence the activation of mental models is priming. Priming was defined by Fiske and Taylor (1984) as "the fact that recently and frequently activated ideas come to mind more easily than ideas that have not been activated" (p. 231). Later Fiske and Taylor (2013) refined their definition of priming, clarifying that priming improves the accessibility of categories. Roskos-Ewoldsen et al. (2002) argued that mental models explain priming. On the one hand, mental models can incorporate the information delivered with the prime (Wyer Jr and Radvansky 1999; Zwaan and Radvansky 1998). On the other hand, primes increase the accessibility of the targeted mental model, which increases the likelihood of its activation (Brewer et al. 2003; Iyengar and Kinder 1987). Following up on this idea, subtle primes could cause the activation of eco-driving mental models and change subsequent judgements and behaviour (cf. Brewer et al. 2003; Iyengar and Kinder 1987) to achieve some degree of fuel savings with cost-efficient means. Although many drivers' eco-driving mental models might warrant improvement, they are able to effectively 
reduce fuel consumption. Studying their activation can shed more light on what combination of training and reminding can efficiently achieve drivers' fuel-saving potential.

\subsection{The current study}

In a recent driving simulator study (Pampel et al. 2015), it was found that regular drivers employed eco-driving skills when they were asked to drive fuel-efficiently, and were also able to report on effective techniques. The participants consequently reduced their fuel consumption compared to a baseline condition in which they were instructed to drive "normally". In comparison, when asked to drive safely, the drivers' behaviours did not differ from everyday driving, except that participants tended to prioritise braking in tradeoff situations such as approaching a junction with amber traffic lights. However, it was not possible to distinguish safe from "normal" driving in the same way as eco-driving differed from "normal" driving. Therefore, safe driving mental models appeared to be more congruent with "normal" driving and more prevalent than eco-driving mental models. On the basis of that study, it is understood that drivers have ecodriving mental models, but they do not routinely use them. For the current study, it was tested whether it is possible to activate the eco-driving mental models in the long term with regular prime and advice messages. Because it was important that the messages reliably reached the participants and that they did not need to attend to them during driving, they were sent in the form of text messages on mobile phones over a period of 2 weeks. In order to compare possible behaviour changes, the experiment also included messages with primes related to driving safety as well as direct, verbal instructions delivered immediately before driving by the experimenter. These instructions only consisted of the prompt "Drive fuel-efficiently" and did not include further explanations. This condition was added to activate eco-driving mental models within the current set of scenarios and to compare the behavioural changes to the effects of the text messages. Safety primes and safety-relevant scenarios were created to contrast eco-driving with safe driving and identify conflicts between these driving styles. The safety primes also enabled distinguishing the specific effects of eco-driving instructions from the simple introduction of any type of experimental instruction, which can possibly increase attentional resources and improve performance, as drivers deliberately control their behaviour (Trick and Enns 2009). The aim of the interventions was to investigate the effects of differing text messages on subsequent driving performance. Specifically, it was of interest to find out whether and to which degree the different levels of interventions changed eco- and safe driving behaviour, implying an activation of all or a subset of the relevant mental models. Driving behaviour was measured in a driving simulator, which provided a controlled setting allowing the recording of subtle behaviour changes, as well as the elimination of confounding variables of everyday driving such as time pressure or volatile traffic conditions. Four scenarios were created to test a range of possible differences before and after the interventions. In order to test whether safe or eco-driving behaviours were more prevalent during the experimental drives, two of these scenarios were designed to offset these goals against each other.

\section{Methodology}

\subsection{Design}

A two-way $(2 \times 4)$ mixed design was employed with Drive as within-subjects factor (two levels- -Drive 1" and "Drive 2 "). The between-subjects factor accounting for the text message interventions was intervention (four levels). The participants were divided into an eco-general texts (eco-driving primes), an eco-behaviour texts (eco-driving advice), a safety-general texts (safety primes) and an experimenter instruction group, as listed in Table 1. The safety-general group was added as a comparison to the eco-general texts group, so the effects of the general, non-advisory primes could be compared between these two topics. The ecobehaviour texts group was created to facilitate a comparison between general primes and behavioural advice, designed to improve eco-driving mental models. Instead of receiving text messages, the experimenter instruction group was asked by the experimenter to drive fuel-efficiently as part of the experimental briefing. No further explanations, for example what "fuel-efficient" means, were provided with the instructions. The within-subjects factor Drive refers to the experimental Drives in the driving simulator. The levels consisted of Drive 1 and Drive 2. For Drive 1, the participants were asked to drive as they would everyday ("normally"),

Table 1 Experimental design

\begin{tabular}{lllll}
\hline & Eco-general texts $(n=15)$ & Eco-behaviour texts $(n=13)$ & Safety-general texts $(n=15)$ & Experimenter instruction $(n=15)$ \\
\hline Drive 1 & "Drive normally" & "Drive normally" & "Drive normally" & "Drive normally" \\
Intervention & General eco-driving primes & Behavioural eco-driving advice & General safe driving primes & Experimental instructions \\
Drive 2 & "Drive normally" & "Drive normally" & "Drive normally" & "Drive fuel-efficiently" \\
\hline
\end{tabular}


so this Drive could provide data to measure people's usual driving behaviour as well as to evaluate practice or boredom effects by comparing it with the Drive 2 condition. Similar to Drive 1, the participants were not provided with specific driving-style instructions in Drive 2, except for those in the experimenter instruction group, who were prompted to drive fuel-efficiently.

\subsection{Text message interventions and instructions}

The interventions for 3 of the 4 groups in this study were based on text messages that were sent to the mobile phones of the participants for a period of 2 weeks. The messages served as primes for the drivers to drive eco-friendly and safely and to provide eco-driving advice, depending on the experimental group. Both the primes and advice messages were designed to effect an activation of eco- and safe driving mental models. The prime messages included the topic of fuel efficiency and safety in vehicles, respectively, but no direct behavioural advice. The majority of the topics were selected from recent press releases, for example, of the Institute for Transport Studies. The eco-driving advice messages included well-established advice and also aimed at correcting some of the misconceptions such as the belief that ecodriving is necessarily connected to slow driving. Each participant received 5 messages according to the assigned group and 4 general driving-themed messages. The first one was sent at $8 \mathrm{pm}$ on the day of the first session. Subsequently, one message was sent every second day at $10 \mathrm{am}$, until the last one at 8 am of the day of the second session. The messages were sent in the same order, with intervention and filler messages alternating. In order to assure that the messages were read, the receivers were prompted to reply with "yes" or "no". A list of the text messages is displayed in Table 2.

\subsection{Driving scenarios}

The experimental road was about $18 \mathrm{~km}$ long and provided for a drive of about $30 \mathrm{~min}$. The road consisted of one lane in each direction, leading the participants through urban and rural sections. There was no traffic in the participants' lane, except for the crossing car scenario. The posted speed limits were $30 \mathrm{mph}(48 \mathrm{~km} / \mathrm{h}), 40 \mathrm{mph}(64 \mathrm{~km} / \mathrm{h})$ and $60 \mathrm{mph}$ $(97 \mathrm{~km} / \mathrm{h})$.

Four scenarios were developed. Two of them, Table 3, were designed to primarily provide the possibility for ecodriving and 2 for safe driving. For the former, safety-critical situations were prevented with the absence of surrounding vehicles in the participants' trajectory. These scenarios were applicable to study behaviours such as accelerating, cruising, and decelerating, as well as the driver's speed choice. All these scenarios occurred once in each Drive.
The scenarios described in Table 4 were designed to create a conflict between safe and eco-driving. If drivers attempted to keep a constant speed in these scenarios, safety would be compromised. These scenarios involved other cars and a speed limit decrease followed by a sharp bend, and potentially caused shorter safety margins. The crossing car event was triggered when the participant vehicle crossed a specified value for time to contact (TTC) with the junction. This means that such scenarios ensured conflicts, even when drivers approached them at lower speeds.

\subsection{Hypotheses}

\subsubsection{Hypotheses for eco-driving-relevant scenarios}

Participants who received general eco-themed messages were hypothesised to change their behaviour and lower their fuel consumption by milder accelerations and decelerations, coasting, and also to drive at lower speeds. It was expected that behavioural advice causes a refinement of eco-driving mental models and larger fuel savings compared to the general primes. Accordingly, the participants in this group were expected not to apply excessively low speeds or accelerations. The members of the safety-general texts group were hypothesised to change their behaviour in some regards and improve their fuel consumption slightly by adhering to the speed limits, gently decelerating and leaving longer safety margins. Usually, these safety margins can serve as margins for eco-driving, too, for example, to avoid stepping on the brake. The experimenter instruction group was expected to display the strongest behaviour changes, due to the directly prompted activation of eco-driving mental models.

\subsubsection{Hypotheses for safety-relevant scenarios}

In safety-relevant scenarios, the participants had to tradeoff safety and eco-driving. During eco-driving, drivers were expected to aim for the maintenance of a constant speed. They may keep a longer mean headway during car-following, but tolerate when the headway temporally becomes very short, for example when a car is cutting in the front, to avoid braking. A speed limit decrease can have implications for eco-driving as well, as drivers may be tempted to postpone using the brake pedal and compromise safety by driving too fast when passing the traffic sign. Safety primes were hypothesised to lead to increased driving safety such as a stronger adherence to the speed limits. In some cases, safe driving behaviour can be distinguished from eco-driving, for example, when stronger speed adjustments can help maintaining safety margins, for example, in the case of the crossing car. 
Table 2 Text messages and experimental instructions

General eco-driving primes (eco-general texts group)

"The Dutch city of Helmond saves $15 \%$ of fuel using intelligent traffic lights that change to keep traffic moving. Would you prefer such traffic lights in your area? Text yes or no"

"Reducing carbon emissions in the transport sector has been challenging. Since 1990 only a reduction of $1.7 \%$ has been achieved. Would you support stronger legal restrictions for car manufacturers to achieve larger reductions? Text yes or no"

"Driving in urban conditions can be inefficient, particularly for diesel vehicles. Do you avoid driving on urban roads where possible? Text yes or no"

"Satellite navigation systems can suggest fuel-efficient routes. Would you try such an eco-route? Text yes or no"

"Vehicle emissions can increase local air pollution levels. Do you find there is too much traffic in your area? Text yes or no"

Behavioural eco-driving advice (eco-behaviour texts group)

"Increasing your distance to the car in front, so you pass the same landmark after $3 \mathrm{~s}$, can help you maintaining a steady speed and save fuel. Is this advice helpful? Text yes or no"

"Use engine braking while you approach curves and junctions and avoid slamming on your brakes. Are you practising driving like this? Text yes or no"

"For fuel-efficient driving you may accelerate up to speed swiftly, but not aggressively. Have you tried this? Text yes or no"

"Eco-driving is not always slow driving. It is often wiser to get up to an efficient speed and keep steady. Would you try this? Text yes or no"

"Gently accelerate before a hill and step off the gas pedal before reaching the top. Coast downhill to save fuel. Have you given this a chance? Text yes or no"

General safety primes (safety-general texts group)

"In the UK the injury rate of cyclists and pedestrians is high compared with other European countries. Do/would you feel safe walking or cycling? Text yes or no"

"Imagine your car communicates with the road and other vehicles to increase safety, particularly at junctions. Would you worry about your privacy? Text yes or no"

"Cars will soon be able to take over control in case of a sudden obstacle, and automatically steer around it. Would feel safer with this feature? Text yes or no"

"Several cities in the UK consider organising buses and cyclists in dedicated lanes, separate from cars, designed to increase the safety of all road users. Would you support (more) segregated infrastructure in your area? Text yes or no"

"Young drivers are particularly prone to accidents. Do you support an increase in the minimum age for driver's licenses to increase road safety? Text yes or no"

Filler messages (all three text groups)

"From 2007 to 2011, the number of cars purchased by people aged 18 to 34 fell almost 30\%. Are cars too expensive for young people? Text yes or no"

"Partly automated cars need to constantly monitor the driver to ensure they are able to take over control at any time. Would you feel uneasy? Text yes or no"

" "Range anxiety' is the term used to describe the concern about the remaining battery charge in electric vehicles. Do you think there are enough charging stations for electric vehicles in your area? Text yes or no"

"Predicting traffic flows is a large research field in the UK. Would you say football games have a strong influence on the amount of traffic? Text yes or no"

Experimental eco-driving instructions (experimenter instruction group)

Instead of receiving text messages, the participants were instructed to eco-drive by the experimenter. The experimental instructions involved the following:

They were provided in person by the experimenter

They were provided immediately before driving, when the participant was seated in the simulator

They were formulated in a direct way ("Drive fuel-efficiently")

No further details or explanations were included

\subsection{Apparatus}

This research employed the motion-based version of the University of Leeds Driving Simulator (University of Leeds 2013). According to the AIDE project (RiminiDöring et al. 2005), the simulator is classified as a type $\mathrm{E}$, or advanced, system. It is based on a Jaguar S-type vehicle with fully operational controls, including a real steering wheel with force feedback and pedals, as well as rear view and side mirrors. This is facilitated with a cab of a Jaguar S-type vehicle placed inside a dome, shown in Fig. 1, which provides the projection area for a spherical screen, showing the road environment at $60 \mathrm{~Hz}$ and a resolution of $3 \times 1920 \times 1200$ to the front and $1024 \times 768$ in the peripheral and rear views. The drivers face a horizontal field view of $266^{\circ}$. The rear view and side mirrors provide a field view of $42^{\circ}$, which is displayed on and therefore only visible through these mirrors. While driving, the participant can perceive forces caused by braking and cornering, as well as rough patches on roads and bumps. An immersive sound system with a speaker mimics the sound of the vehicle's engine and other road 
Table 3 Scenarios primarily relevant for eco-driving

\begin{tabular}{ll} 
Road layout & Scenario description \\
\hline Acceleration & $\begin{array}{c}\text { The participant was stationary at a red traffic light that then switched } \\
\text { to green. They then accelerated to the speed limit } \\
\text { Data capture commenced when the traffic light turned green and } \\
\text { ended approximately } 350 \mathrm{~m} \text { later } \\
\text { Dependent variables } \\
\text { Mean and variation of acceleration }\end{array}$ \\
Cruising & $\begin{array}{c}\text { The cruising scenario consisted of road sections with slight curves, } \\
\text { 250 m long. This scenario occurred several times in urban sections } \\
\text { with a speed limit of } 30 \text { mph. Cruising involved free flow driving } \\
\text { with no traffic lights present. The scenario had the secondary pur- } \\
\text { pose to create space between the scenarios involving junctions } \\
\text { Dependent variables } \\
\text { Fuel consumption, mean speed, mean acceleration, variation of } \\
\text { acceleration and deceleration }\end{array}$
\end{tabular}

Table 4 Driving scenarios with conflicts between eco- and safe driving

Scenario description
Crossing car

noise. The dome is attached to a motion system with eight degrees-of-freedom.

In order to ensure a smooth handling of the text messages during the experiment, the online service BulkSMS was used. The service allows sending messages larger than 160 characters, where needed, scheduling as well as receiving replies from participants. Participants were expected to provide their own mobile phones with UK numbers, which was verified in the confirmation email sent during the booking process for the study.

\subsection{Participants}

Participants were recruited utilising the participant databases of the University of Leeds Driving Simulator as well as the Institute for Psychological Sciences. A total of 62 people were recruited, but four of them dropped out due to 

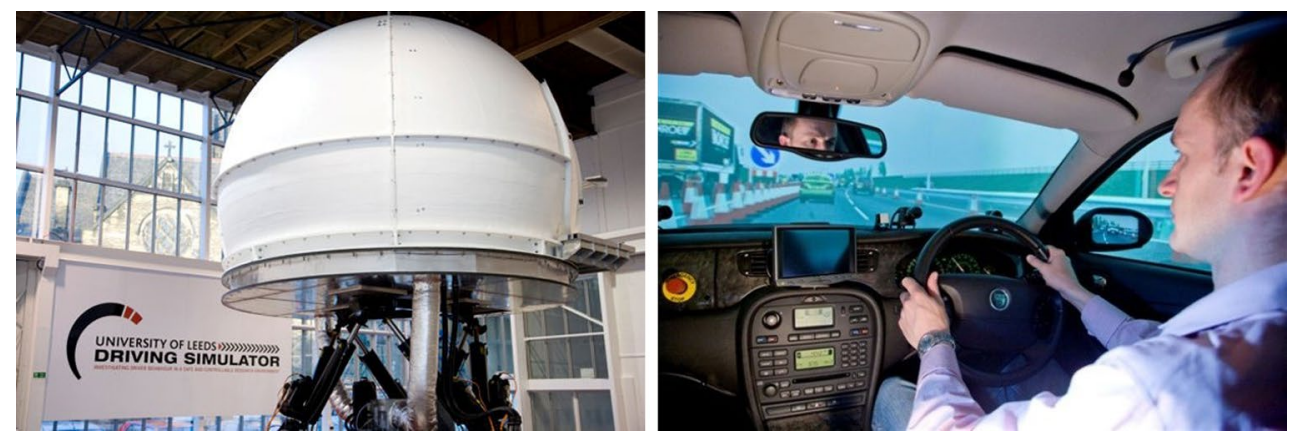

Fig. 1 The University of Leeds Driving Simulator (University of Leeds 2013)

scheduling issues. The final sample consisted of 58 drivers, between 21 and 63 years old (mean age 34.5 years, SD 11.6 years), 35 of them male (mean age 32.0 years) and 23 of them female (mean age 38.4 years). Every participant drove at least 1000 miles per year (mean annual mileage was 8395 miles) and held a full EU license for at least 2 years (mean driving experience was 13.9 years). A breakdown of the demographic information per experimental group is provided in Table 5. As a gesture of appreciation, all participants were given $£ 20$.

\subsection{Procedure}

During recruitment, the participants were told that the study was about "driving styles", without mentioning the ecodriving focus, to prevent the participants from preparing for the study. When the appointments were confirmed, the participants were randomly assigned to an intervention group and an email was sent to them. Those in the eco-general texts, eco-behaviour texts and safety-general texts groups were told that the study involved regular text messages on their mobile phones for 2 weeks, at least every $48 \mathrm{~h}$. The email also informed the participants of their right to withdraw from the study at any point in time. At the beginning of the first session, the participants were briefed and asked to sign a consent form. Together with the experimenter, the participants performed a practise drive to become familiar with the driving simulator. The scenarios involving junctions and other vehicles in the participant's trajectory were not included in the practise drive to prevent the participant from expecting them. For the first experimental Drive, each participant was asked to drive through a combined urban and rural section without specific instructions regarding their driving style, so it could be assessed prior to the interventions. The road layout, thus the sequence of scenarios, was the same for each driver, and the Drive lasted around $30 \mathrm{~min}$. Subsequently, the participants were given questionnaires enquiring about their demographic information.

After the first session, the intervention took place according to the assigned group. For a period of 2 weeks, a text message was sent to each participant, except for the experimenter instruction group, at least every 2 days. At the end of the period, the participants were scheduled for a second session in the driving simulator and were sent a reminder text message for this appointment 2 days in advance. The second session began with an experimental Drive, for $30 \mathrm{~min}$. For this Drive, the participants were asked to drive normally, except for the experimenter instruction group, which was asked to drive fuel-efficiently. At the end of the second session, a debriefing took place and the participants had the opportunity to ask questions about the study.

\subsection{Data analysis}

The raw data collected by the driving simulator were processed in Matlab to extract the dependent variables, for the whole Drives and separately for each scenario. Speed and the $x$ - and $y$-positions of the vehicle on the roadway were

Table 5 Participant demographic information per experimental group

\begin{tabular}{lllllr}
\hline & Age (years) & $\begin{array}{l}\text { Standard deviation of } \\
\text { age (years) }\end{array}$ & $\begin{array}{l}\text { Annual mileage } \\
\text { (miles) }\end{array}$ & $\begin{array}{l}\text { Driving experience } \\
\text { (years) }\end{array}$ & Number \\
\hline Eco-general texts & 32.0 & 9.9 & 9036 & 10.3 & $15(10$ male, 5 female) \\
Eco-behaviour texts & 37.9 & 13.5 & 7500 & 18.2 & $13(7$ male, 6 female $)$ \\
Safety-general texts & 34.6 & 10.5 & 9033 & 15.1 & $15(9$ male, 6 female $)$ \\
Experimenter instruction & 33.6 & 13.6 & 7933 & 12.2 & $15(9$ male, 6 female $)$ \\
\hline
\end{tabular}


used to model fuel consumption. It was approximated with the microscopic Passenger car and Heavy-duty Emission Model PHEM (Rexeis et al. 2005). Although the engine model of the driving simulator software is based on a Jaguar $\mathrm{X}$-type, with braking data from a Ford Mondeo, a more typical car was assumed for calculating the fuel consumption, a Ford Mondeo Ghia with a 16 V, Euro 5 petrol engine. In a previous study using the same driving simulator software (Pampel et al. 2015), this approach resulted in a number of plausible significant differences between the experimental conditions.

For the behavioural measures, a mixed method ANOVA was performed, with the within-subjects factor Drive (two levels: Drive 1 and Drive 2), and the between-subjects factor Instruction (four levels: eco-general texts, eco-behaviour texts, safety-general texts and experimenter instruction). Instruction effects were further investigated with post hoc pairwise comparisons. Interaction effects were unpicked with $t$ tests comparing the Drive 1 and Drive 2 measures for each group. In order to assure that significant effects were not due to differences between the intervention groups in Drive 1, a separate one-way ANOVA was conducted with data from Drive 1 only. When assumptions of parametric testing were violated, nonparametric methods were used with the Wilcoxon signed-rank test on Drive and the Kruskal-Wallis test on Instruction. In the case of multiple tests, the results were Bonferroni-corrected. Statistical significance was accepted at $p<0.05$.

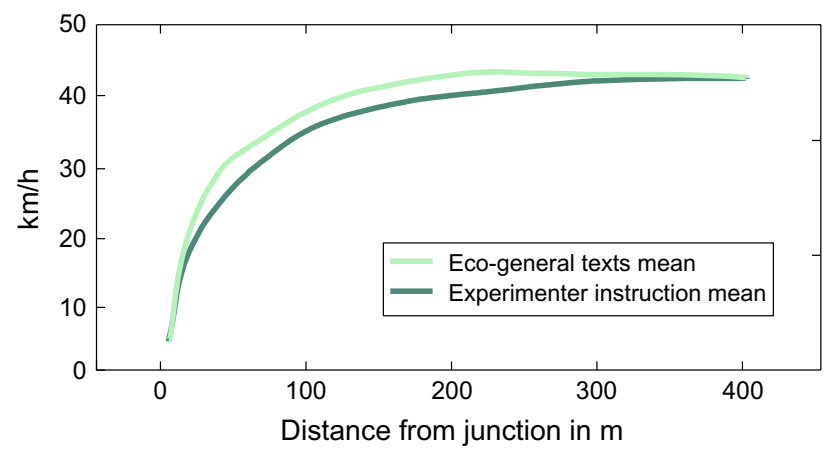

Fig. 2 Speed profile in the acceleration scenario

\section{Results}

Across the entire drive, there were no main effects on either fuel consumption (Drive: $p=.446$, intervention: $p=.766$ ) or total time (Drive: $p=.913$, intervention: $p=.894$ ). Each of the scenarios was then considered separately.

\subsection{Acceleration scenario}

Figure 2 shows the speed profiles in the acceleration scenario for the group instructed to eco-drive, compared to the group receiving eco-driving prime messages.

In this scenario, several effects could be attributed to the interventions. For mean acceleration, a Drive*Intervention interaction effect was found $[F(3,50)=3.049, p=.037$, $\left.\eta^{2}=.155\right]$ with the experimenter instruction group reducing the acceleration rate by $19 \%$ in Drive $2[t(14)=3.343$, $p=.010, r=.666]$. In order to analyse the mean acceleration in isolation, an ANCOVA was conducted with the mean cruising speed in the Drive 2 condition as covariate. The result showed that the cruising speed affected the speed, and the Drive*Intervention became non-significant ( $p=.054$ ).

Another Drive*Intervention interaction effect for the standard deviation of acceleration, or the acceleration variation, when setting off after stopping at a junction $[F(3$, $\left.50)=3.396, p=.025, \eta^{2}=.169\right]$. In order to further investigate the nature of the interaction effect, $t$ tests were performed, comparing Drive 1 and Drive 2. These were significant for the experimenter instruction group $[t(14)=3.772$, $p=.004, r=.710]$. This means that the group that received experimental eco-driving instructions accelerated $30 \%$ more smoothly. Table 6 lists the values for the average as well as the variation of acceleration in the scenario.

\subsection{Cruising scenario}

There were no significant main effects of Drive and intervention for mean fuel consumption for the cruising scenario. However, for the time spent in this scenario a Drive*Intervention interaction effect could be identified $\left[F(3,50)=3.828, p=.015, \eta^{2}=.187\right]$. Especially for the group instructed to eco-drive by the experimenter, this time

Table 6 Drive 1 to Drive 2 changes for the acceleration scenario

\begin{tabular}{|c|c|c|c|c|c|c|c|}
\hline Variable & Eco-general & Eco-behaviour & Safety-general & Instruction & Significant differences & $p$ & $\eta_{p}^{2} / r$ \\
\hline \multirow[t]{3}{*}{ Mean acceleration $\left(\mathrm{m} / \mathrm{s}^{2}\right)$} & \multirow[t]{3}{*}{0.05} & \multirow[t]{3}{*}{0.02} & \multirow[t]{3}{*}{0.02} & \multirow[t]{3}{*}{-0.09} & Drive & .956 & $\mathrm{n} / \mathrm{a}$ \\
\hline & & & & & Intervention & .444 & $\mathrm{n} / \mathrm{a}$ \\
\hline & & & & & Drive*Intervention & .037 & .155 \\
\hline \multirow[t]{3}{*}{ SD of acceleration $\left(\mathrm{m} / \mathrm{s}^{2}\right)$} & \multirow[t]{3}{*}{0.07} & \multirow[t]{3}{*}{-0.01} & \multirow[t]{3}{*}{0.03} & \multirow[t]{3}{*}{-0.14} & Drive & .477 & $\mathrm{n} / \mathrm{a}$ \\
\hline & & & & & Intervention & .686 & $\mathrm{n} / \mathrm{a}$ \\
\hline & & & & & Drive*Intervention & .025 & .169 \\
\hline
\end{tabular}


Table 7 Drive 1 to Drive 2 changes for the cruising scenario

\begin{tabular}{|c|c|c|c|c|c|c|c|}
\hline Variable & Eco-general & Eco-behaviour & Safety-general & Instruction & Significant differences & $p$ & $\eta_{p}^{2} / r$ \\
\hline \multirow[t]{3}{*}{ Fuel consumption $(\mathrm{g} / \mathrm{s})$} & \multirow[t]{3}{*}{-0.008} & \multirow[t]{3}{*}{-0.013} & \multirow[t]{3}{*}{-0.024} & \multirow[t]{3}{*}{-0.022} & Drive & .194 & $\mathrm{n} / \mathrm{a}$ \\
\hline & & & & & Intervention & .508 & $\mathrm{n} / \mathrm{a}$ \\
\hline & & & & & Drive*Intervention & .997 & $\mathrm{n} / \mathrm{a}$ \\
\hline \multirow[t]{3}{*}{ Time (s) } & \multirow[t]{3}{*}{-7} & \multirow[t]{3}{*}{2} & \multirow[t]{3}{*}{-7} & \multirow[t]{3}{*}{27} & Drive & .271 & $\mathrm{n} / \mathrm{a}$ \\
\hline & & & & & Intervention & .879 & $\mathrm{n} / \mathrm{a}$ \\
\hline & & & & & Drive*Intervention & .015 & .187 \\
\hline \multirow[t]{3}{*}{ Mean speed (m/s) (mph) } & \multirow[t]{3}{*}{$0.1(1)$} & \multirow[t]{3}{*}{$0.0(0)$} & \multirow[t]{3}{*}{$0.1(0)$} & \multirow[t]{3}{*}{$-0.5(-1)$} & Drive & .322 & $\mathrm{n} / \mathrm{a}$ \\
\hline & & & & & Intervention & .891 & $\mathrm{n} / \mathrm{a}$ \\
\hline & & & & & Drive*Intervention & .018 & .180 \\
\hline \multirow[t]{3}{*}{$\mathrm{SD}$ of acceleration $\left(\mathrm{m} / \mathrm{s}^{2}\right)$} & \multirow[t]{3}{*}{0.002} & \multirow[t]{3}{*}{-0.005} & \multirow[t]{3}{*}{0.004} & \multirow[t]{3}{*}{-0.052} & Drive & .034 & .087 \\
\hline & & & & & Intervention & .508 & $\mathrm{n} / \mathrm{a}$ \\
\hline & & & & & Drive*Intervention & .025 & .170 \\
\hline \multirow[t]{3}{*}{ SD of deceleration $\left(\mathrm{m} / \mathrm{s}^{2}\right)$} & \multirow[t]{3}{*}{-0.019} & \multirow[t]{3}{*}{-0.047} & \multirow[t]{3}{*}{-0.024} & \multirow[t]{3}{*}{-0.077} & Drive & .010 & .126 \\
\hline & & & & & Intervention & .234 & $\mathrm{n} / \mathrm{a}$ \\
\hline & & & & & Drive*Intervention & .314 & $\mathrm{n} / \mathrm{a}$ \\
\hline
\end{tabular}

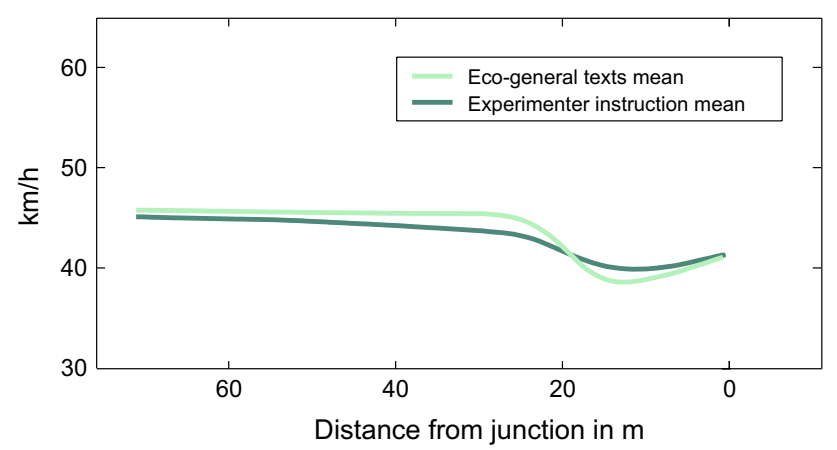

Fig. 3 Speed profile for the eco-general texts and the experimenter instruction groups in Drive 2 in the crossing car scenario

increased to $15: 06 \mathrm{~min}$, and a $t$ test comparing the Drive 1 and Drive 2 means proves this difference to be significant $[t(14)=-2.688, p=.036, r=.583]$.
For the mean speed in the cruising scenario, there was a Drive*Intervention interaction effect $[F(3,50)=3.655$, $\left.p=.018, \eta^{2}=.180\right]$ with the largest average reduction, $1 \mathrm{mph}$, for the group that received experimental eco-driving instructions. A $t$ test confirmed this reduction to be significant $[t(14)=2.671, p=.036, r=.581]$.

The analysis of the variation of acceleration resulted in several significant effects, for Drive $[F(1,50)=4.758$, $\left.p=.034, \eta^{2}=.087\right]$ and for the interaction between Drive*Intervention $\left[F(3,50)=3.404, p=.025, \eta^{2}=.170\right]$. A closer look at the interaction effect shows that the acceleration was smoothened by $20 \%$ between Drive 1 and Drive 2 Drive for the experimenter instruction group, and a $t$ test confirmed the difference for this group $[t(14)=2.835$, $p=.026, r=.604]$.

For the smoothness of deceleration, a main effect for Drive was found $\left[F(1,50)=7.235, p=.010, \eta^{2}=.126\right]$. The participants drove smoother in Drive 2 , most substantially by $25 \%$ in the experimenter instruction group. Yet, comparisons

Table 8 Drive 1 to Drive 2 changes for the crossing car scenario

\begin{tabular}{|c|c|c|c|c|c|c|c|}
\hline Variable & Eco-general & Eco-behaviour & Safety-general & Instruction & Significant differences & $p$ & $\eta_{p}^{2} / r$ \\
\hline \multirow[t]{3}{*}{ Mean deceleration $\left(\mathrm{m} / \mathrm{s}^{2}\right)$} & \multirow[t]{3}{*}{0.258} & \multirow[t]{3}{*}{-0.114} & \multirow[t]{3}{*}{0.356} & \multirow[t]{3}{*}{0.118} & Drive & .019 & .016 \\
\hline & & & & & Intervention & .209 & $\mathrm{n} / \mathrm{a}$ \\
\hline & & & & & Drive*Intervention & .613 & $\mathrm{n} / \mathrm{a}$ \\
\hline \multirow[t]{3}{*}{ SD of deceleration $\left(\mathrm{m} / \mathrm{s}^{2}\right)$} & \multirow[t]{3}{*}{-0.27} & \multirow[t]{3}{*}{-0.06} & \multirow[t]{3}{*}{-0.43} & \multirow[t]{3}{*}{-0.27} & Drive & .002 & .170 \\
\hline & & & & & Intervention & .230 & $\mathrm{n} / \mathrm{a}$ \\
\hline & & & & & Drive*Intervention & .483 & $\mathrm{n} / \mathrm{a}$ \\
\hline \multirow[t]{3}{*}{ Max. brake pressure $(N)$} & \multirow[t]{3}{*}{-22.2} & \multirow[t]{3}{*}{-2.4} & \multirow[t]{3}{*}{-20.8} & \multirow[t]{3}{*}{-12.3} & Drive & .034 & .087 \\
\hline & & & & & Intervention & .489 & $\mathrm{n} / \mathrm{a}$ \\
\hline & & & & & Drive*Intervention & .737 & $\mathrm{n} / \mathrm{a}$ \\
\hline
\end{tabular}


for the groups did not confirm any reduction to be significant ( $p=.214$ for experimenter instruction). The changes between the Drives are provided in Table 7.

\subsection{Crossing car scenario}

The crossing car scenario presented a trade-off between safe and eco-driving by making it unsafe to maintain a constant speed. The scenario involved a car crossing the road in front of the participant. In Fig. 3, the speed profiles for the group instructed to drive fuel-efficiently and the group that received the eco-driving prime messages are depicted.

Several main effects occurred for Drive, see Table 8. For instance, the mean deceleration was reduced in Drive $2\left[F(1,50)=5.923, p=.019, \eta^{2}=.106\right]$, with $38 \%$ particularly for the safety-general texts group. Although its mean deceleration was relatively high before the intervention, the Drive 1 measure was not significantly different from the other groups'. Comparisons between Drive 1 and Drive 2 only support a reduction for the experimenter instruction group $[t(14)=-2.566, p=.044, r=.566](p=.312$ for safety-general texts).

A Drive effect for the variation of deceleration indicated a reduction for the second session $[F(1,50)=10.243, p=.002$, $\left.\eta^{2}=.170\right]$. When Drive 1 and Drive 2 values were compared for each group, a Wilcoxon signed-rank test confirmed that the difference of $32 \%$ for the eco-general texts group was significant $[Z(15)=-2.499, p=.048,-.645]$. In addition, the experimenter instruction group decelerated significantly more smoothly, by $42 \%[t(14)=2.938, p=.022, r=.785]$.

The maximum brake pedal pressure was lowered during Drive 2 , supported by a main effect $[F(1,50)=4.775$, $\left.p=.034, \eta^{2}=.087\right]$. A Wilcoxon signed-rank test confirmed a significant reduction for the eco-general texts group [50\%, $Z(15)=-2.499, p=.048, r=-.645]$ and Safe [44\%, $Z(15)=-2.668, p=.032, r=-.689]$.

\subsection{Decreasing speed limit scenario}

This scenario was considered safety-critical, as it involved a decrease of the speed limit from 60 to $40 \mathrm{mph}$ and could subject a driver to a trade-off between a constant speed and a safe adherence to the speed limit. The mean speed was lowered during Drive $2[F(1,50)=13.874, p<.001$, $\left.\eta^{2}=.217\right]$, with $t$ test showing significant reductions for the Safe $[t(14)=2.934, p=.044, r=.617]$ and experimenter instruction groups $[t(14)=3.156, p=.014, r=.645]$.

All groups drove past the traffic sign with a lower speed in Drive $2\left[F(1,50)=15.493, p<.001, \eta^{2}=.237\right]$. $T$ - and Wilcoxon signed-rank tests revealed significant reductions for the safety-general texts $[t(14)=3.338$, $p=.020, r=.666]$ and the experimenter instruction groups $[Z(15)=-2.897, p=.008, r=-.748]$. An intervention effect $\left[F(3,50)=3.150, p=.033, \eta^{2}=.159\right]$ occurred, with pairwise comparisons showing a significant difference between the eco-general texts and eco-behaviour texts group $(p=.028)$.

For mean deceleration, there was a main effect for Drive $\left[F(1,50)=4.357, p=.042, \eta^{2}=.080\right] . T$ tests confirmed a significantly stronger deceleration in Drive 2 for the experimenter instruction group [ $t(14)=2.764, p=.030, r=.594]$, with an increase of $47 \%$. An intervention effect could be identified as well $\left[F(3,50)=3.271, p=.029, \eta^{2}=.164\right]$. Pairwise comparisons clarified that the absolute value was higher for the eco-general texts than for the eco-behaviour texts group $(p=.033)$. It differed by $58 \%$ in Drive 2 .

There were several effects for the smoothness of deceleration. An intervention effect was found $[F(3,50)=6.049$, $\left.p=.001, \eta^{2}=.266\right]$ with pairwise comparisons revealing that the eco-general texts group drove more erratically than the other groups [eco-behaviour texts: $p=.003$, Safe: $p=.009$, Instruction: $p=.011$ )], but the intervention effect was already present in the Drive 1 condition

Table 9 Drive 1 to Drive 2 changes for the decreasing speed limit scenario

\begin{tabular}{|c|c|c|c|c|c|c|c|}
\hline Variable & Eco-general & Eco-behaviour & Safety-general & Instruction & Significant differences & $p$ & $\eta_{p}^{2} / r$ \\
\hline \multirow[t]{3}{*}{ Mean speed $(\mathrm{m} / \mathrm{s})(\mathrm{mph})$} & \multirow[t]{3}{*}{$-0.6(-1)$} & \multirow[t]{3}{*}{$-0.3(-1)$} & \multirow[t]{3}{*}{$-1.2(-2)$} & \multirow[t]{3}{*}{$-0.9(-2)$} & Drive & $<.001$ & .217 \\
\hline & & & & & Intervention & .207 & $\mathrm{n} / \mathrm{a}$ \\
\hline & & & & & Drive*Intervention & .372 & $\mathrm{n} / \mathrm{a}$ \\
\hline \multirow[t]{3}{*}{ Speed at traffic sign $(\mathrm{m} / \mathrm{s})(\mathrm{mph})$} & \multirow[t]{3}{*}{$-0.4(-1)$} & \multirow[t]{3}{*}{$-0.3(-1)$} & \multirow[t]{3}{*}{$-1.8(-4)$} & \multirow[t]{3}{*}{$-1.6(-4)$} & Drive & $<.001$ & .237 \\
\hline & & & & & Intervention & .033 & .159 \\
\hline & & & & & Drive*Intervention & .107 & $\mathrm{n} / \mathrm{a}$ \\
\hline \multirow[t]{3}{*}{ Mean deceleration $\left(\mathrm{m} / \mathrm{s}^{2}\right)$} & \multirow[t]{3}{*}{0.023} & \multirow[t]{3}{*}{-0.029} & \multirow[t]{3}{*}{-0.188} & \multirow[t]{3}{*}{-0.111} & Drive & .042 & .080 \\
\hline & & & & & Intervention & .029 & .164 \\
\hline & & & & & Drive*Intervention & .063 & $\mathrm{n} / \mathrm{a}$ \\
\hline \multirow[t]{3}{*}{ SD of deceleration $\left(\mathrm{m} / \mathrm{s}^{2}\right)$} & \multirow[t]{3}{*}{-0.084} & \multirow[t]{3}{*}{0.022} & \multirow[t]{3}{*}{0.033} & \multirow[t]{3}{*}{0.023} & Drive & .667 & $\mathrm{n} / \mathrm{a}$ \\
\hline & & & & & Intervention & .001 & .266 \\
\hline & & & & & Drive*Intervention & .039 & .153 \\
\hline
\end{tabular}


$\left[F(3,54)=3.617, p=.019, \eta^{2}=.167\right]$. A Drive*Intervention interaction effect showed that, on average, the eco-general texts group then reduced their standard deviation of deceleration in the second Drive, contrary to the others $\left[F(3,50)=3.011, p=.039, \eta^{2}=.153\right]$. However, a Wilcoxon signed-rank test did not confirm the significance of this reduction $(p=.560)$. All effects are listed in Table 9 .

\section{Discussion}

For the current study, the activation of eco-driving mental models was attempted using text messages, containing primes and advice about eco-driving. In order to compare possible behaviour changes, the experiment also included conditions with primes related to driving safety, as well as simple instructions delivered verbally by the experimenter. The instructions did not include further explanations regarding eco-driving and were designed to provide a condition in which eco-driving mental models were activated, and to which the other interventions could be compared to. To what extend this activation was achieved is discussed in Sect. 4.1. The aim of the text messages was to find out whether and to what degree primes changed eco- and safe driving behaviour, implying an activation of all or a subset of the relevant mental models. Driving behaviour was measured in a variety of scenarios using a motion-based driving simulator before and after the interventions. In order to test whether safe or eco-driving behaviours were more prevalent during the second Drive, a number of scenarios were designed that required drivers to potentially offset these goals against each other.

\subsection{Effects of experimental instructions on eco-driving}

The strongest effects of the four levels of intervention were apparent in the experimenter instruction group. Because no further explanations were given, these effects suggest that the drivers in this group activated their eco-driving mental models and consequently applied their existing eco-driving knowledge and skills. The experimenter instruction group spent more time in the cruising section and drove more slowly. When setting off from stopping at a junction, this group lowered both the mean and the variation of acceleration, although the change in the acceleration rate was partly confounded by the lower cruising speed. This group also accelerated and decelerated less erratically when cruising, although the change for deceleration was not significant. When a car crossed in front, this group decelerated in a milder and smoother manner. These behavioural changes towards lower speed and smoother speed changes, provoked by asking drivers to eco-drive, are consistent with previous studies (Birrell et al. 2010; Pampel et al. 2015; van der Voort et al. 2001; Waters and Laker 1980). However, no significant effects on fuel consumption could be found, neither for the entire Drives, nor regarding the cruising scenario separately. This could be attributed to inefficient behaviours such as driving too slowly, for example below a speed limit of $30 \mathrm{mph}$ (Samaras and Ntziachristos 1998), and accelerating too mildly (Mensing et al. 2013, 2014). In a questionnaire study by McIlroy and Stanton (2017), 11.8\% of the respondents were incorrectly stating low speeds as eco-driving practice, while $10.6 \%$ worry about the impacts on travel time. The nature of the driving scenarios could have played a role as well, as they did not provide many opportunities to plan behaviour ahead. For example, slowly approaching a junction with red traffic lights did not prevent the participants from stopping, because the scenario was designed for the car to stop. Similarly, events such a car crossing the road were triggered by the participants' approach. Hence, their effect on speed fluctuations could not be avoided with anticipatory behaviours. At last, the fuel consumption modelling with PHEM could have contributed to the lack of effects for several reasons. The model is based on real-world measurements, which might not have been exact, the approximations in the simulator's vehicle rendering as well as the assumptions regarding the used vehicle model and type.

\subsection{Effects of text messages on eco-driving}

The groups receiving general eco-driving primes and specific eco-driving advice displayed some behavioural changes, but these were not consistent enough to be classified as eco-driving. For example, in line with typical eco-driving behaviours, this group reduced the variation of deceleration as well as the maximum brake pedal pressure when a car crossed the road in front of them. When the speed limit decreased, this group also managed to decelerate smoother, although this effect was confounded by erratic decelerations in the Drive 1 condition. In sum, among the range of scenarios and measures, these effects do not stand out. For the other measures, there were no notable significant changes for this intervention. Hence, it can be concluded that the text message interventions did not have the desired effect on the activation of eco-driving mental models.

Possible explanations for the absence of an activation of eco-driving mental models include the timing, the delivery mode, and the lack of directness. Firstly, in studies involving prompts it has been found that these are most effective when provided close to the targeted behavioural decisions (Geller et al. 1971). Other studies investigating the effects of training have shown that the timing can have an influence on the magnitude of behaviour change (Chapman et al. 2002; de Groot et al. 2011; af Wåhlberg 2007). Similar issues may also occur when eco-driving feedback is delayed (Rolim et al. 2016). For the present experiment, it was assumed 
that sending the last message at 8 am on the day of the second appointment would be sufficiently close. However, those few hours between the message and the actual driving session could have provided sufficient time, and topics to think about, for the participants to forget about eco-driving. Rasmussen (1979) argued that stress, and also simple mindwandering can result in a deactivation of unfamiliar mental models and consequently a reversion to well-learned, more automated behaviours. Secondly, it is possible that text messages are less effective than messages delivered by a person. The human brain responds differently to voice (Latinus and Belin 2011), which enhances the interaction with a message, potentially leading to more trust and increased adherence (Large and Burnett 2014). Lastly, it may have been insufficient that the messages were not directly prompting drivers to eco-drive. They were intended to make the drivers think about eco-driving and advise them about it, respectively. However, they did not ask drivers to actually change their behaviour, which is more likely to be effective (Sarason and Minard 1962). Indeed, casual conversations at the end of the study revealed that the text messages inspired some participants to think about eco-driving, but that it did not occur to them to change their driving behaviour. In addition, messages that are in conflict with existing knowledge can result in distrust (Brodje et al. 2013; Risto and Martens 2013). As an alternative explanation, contrast effects could mitigate the effects of the text messages as people change behaviours towards the opposite direction. These effects can occur when a prime is too obvious and the receivers have negative attitudes towards the target behaviours (Herr 1986; Herr et al. 1983; Martin 1986). However, in the case of participants reacting to obvious primes, one would also expect some participants to purposefully please the experimenter (Fiske and Taylor 1984), which was not the case. The variety of the text messages, with different levels of information, cause-andeffect scenario and emotive words could have confounded their perception, depending on personal factors of the driver (Sharples et al. 2015).

The smoother speeds and decelerations of the eco-general texts group could mean that the eco-driving primes increased an activation of a few lower-level mental models which did not require a lot of effort. A study by Beusen et al. (2009) showed that, following an eco-driving course, participants were maintaining behaviours such as coasting longer than other, possibly more effortful behaviours related to acceleration and idling time. However, since the behaviour changes in the eco-general texts group occurred during safety-critical scenarios and were partly confounded by Drive 1 measures, definite conclusions cannot be drawn.

The group that received safety primes changed some of the deceleration measures in Drive 2. For instance, when a car crossed in front, this group lowered their mean deceleration by tendency and reduced its maximum brake pedal pressure significantly. It may be possible that these changes were not related to an activation or deactivation of safe driving mental models. This idea is supported by the strong similarities between "normal" and safe driving behaviour in Pampel et al. (2015). Instead, this behaviour could signify increased familiarity with the driving environment (cf. Martens and Fox 2007), possibly leading to thoughts about other, unrelated topics.

\subsection{Effects of the interventions on safe driving}

Eco-driving text messages and experimental instructions had varying effects on the scenarios relevant for safe driving, with the experimenter instruction group displaying the strongest effects in Drive 2. Approaching a sign indicating a lower speed limit, the instructed group decelerated at a higher rate and their mean speed was lower altogether. Once they passed the sign, their speed was significantly lower than before the intervention. In this case, driving eco-friendly with the early anticipation of a lower speed limit was congruent with safe driving behaviour. There is indeed evidence that slower driving, particularly adhering to speed limits, can reduce crash risk (Taylor et al. 2000). On the other hand, for this and the eco-general texts groups the standard deviation of deceleration decreased in the crossing car scenario. The eco-general texts group also reduced the maximum brake pedal pressure. Despite these situations being safety-critical, smoother decelerations were applied. Hence, eco-driving could have been practised to some degree. However, the isolated effect for the instructed group as well as the absence of more distinct behavioural changes for the groups receiving eco-driving primes and advice indicates that safe driving behaviours were mostly applied in these scenarios.

In these safety-critical scenarios, the safety-general texts group displayed a few behaviour changes towards safer behaviour in Drive 2. The text messages led to a lower mean speed as well as the largest drop in speed when the speed limit decreased. Consequently, the drivers passed the traffic sign with a significantly lower speed. In this case, the safetygeneral texts group adhered more to the speed limits. This would mean that the safety primes were somewhat effective in bringing safe driving behaviour into the drivers' minds when this behaviour was beneficial. One possible explanation for the effectiveness of these messages, compared to eco-driving primes, could be that drivers are more familiar with safe driving. For example, in Pampel et al. (2015) there were no differences between driving behaviour following instructions to drive safely and "normally". Hence, it could have required not as much effort to activate safe driving as to activate eco-driving mental models. These findings could indicate that the text messages employed in this study can be effective, for priming some mental models, but not others. However, these isolated results following text messages 
about driving safety do not allow drawing definite conclusions at this point.

\subsection{General discussion, limitations and future work}

The present research was built upon earlier findings that many drivers already possess a set of eco-driving mental models (Pampel et al. 2015). This study then attempted to activate them with primes and advice, and to compare the effects with experimental instructions. It was found that text messages including these eco-driving primes and advice led to some behavioural changes, but not consistent eco-driving. If drivers do not drive eco-friendly, it is not a simple lack of knowledge and skills (Delicado 2012) or their unwillingness (Delhomme et al. 2013). The problem appears to be connected to routine behaviour, which is inherently difficult to change. Regular drivers are usually very skilled in tasks such as braking, accelerating and car-following. These tasks tend to be automated and can be carried out without conscious attention (Boer and Hoedemaeker 1998; Michon 1985). It is possible to access lower-level behaviour and change it (Vallacher and Wegner 1987). However, bringing mental models from the skill level into consciousness requires effort, and it is convenient to revert back to old behaviours (Rasmussen 1979). There are several ways that have been shown to be able to change drivers' behaviour to eco-driving, and regular feedback has been shown to be particularly effective (Barkenbus 2010). The present study showed that regular reminders do not result in sufficient behaviour changes towards ecodriving. In contrast, experimental instructions provided in person and immediately before driving were much more successful in activating eco-driving mental models.

The driving simulator experiment has a number of limitations. For example, motivations to take part in studies are related to contributing to the research, curiosity about its outcomes and financial rewards (Stunkel and Grady 2011). Participants drive for the study's purpose rather than in order to reach a specific destination under time pressure, for example. Real-world settings could produce different results, on the one hand, due to a plethora of distractions, but also due to small monetary incentives. Hence, findings need to be validated with a larger number of participants and extrapolated into real-world settings.

Future studies can build upon findings of previous research to strengthen the interventions that target the activation of eco-driving mental models. Such studies could increase the frequency of the messages to several times a day (cf. Abrahamse et al. 2005) or time them closer to the point of action (cf. Seligman et al. 1981), for example, by delivering them when the driver gets into the car. A longer time period of at least 3 weeks, as used in text message studies in the health sector (e.g. Cole-Lewis and Kershaw 2010; Stockwell et al. 2013), could result in stronger effects.
Information that makes drivers feel uncomfortable with their usual driving practise could be effective as well (cf. Vallacher and Wegner 1987), for example, using social norms. Considering the finding that verbal instructions were effective in changing behaviour, the question arises whether the messages sent in the present study would be more effective in a vocal (cf. Large and Burnett 2014) and more direct form (cf. Sarason and Minard 1962). The latter could be implemented with messages such as "Drive fuel-efficiently".

Besides "strengthening" the text messages, the experimental instructions could be "weakened" in order to isolate their effective aspects. Using an instrumented car instead of a driving simulator could help the participants feel more natural and unsupervised during driving. It would be interesting to find out whether instructions as employed in this study have the same effects in this situation, before the participants are driving away on their own. Some of the effects found in this experiment can be investigated further. In addition, the behaviour changes following general safety-themed as well as the general eco-driving text messages could be investigated with a larger number of participants in order to find out whether the effects in this study were incidental, or whether they indicate potential of the text messages, for example, for behaviours that are easier to implement.

The ecoDriver project has developed and tested the effectiveness and acceptance of a diverse range of feedback systems (e.g. Jamson et al. 2015a, b). These have been shown to be particularly effective in encouraging eco-driving (Barkenbus 2010). Feedback does not only educate, but also reward, motivate (Seligman et al. 1981) and reinforce new behaviours (Fischer 2008). Interestingly, in a study by Birrell et al. (2014) participants reduced their speed although the employed system did not advise on speed choice. Hence, it would be interesting to investigate why this unforeseen effect was arising. Further research can examine to which degree feedback causes the activation of existing eco-driving mental models. Such studies could control for the types of information provided by a support system. In general, further studies will be necessary to investigate other approaches to activate existing eco-driving mental models and therefore achieve the effects of the experimental instructions.

Acknowledgements The authors acknowledge the support given for this research by the team of the University of Leeds Driving Simulator (UoLDS), and the ecoDriver project Grant Agreement Number: 288611 .

Open Access This article is distributed under the terms of the Creative Commons Attribution 4.0 International License (http://creativecommons.org/licenses/by/4.0/), which permits unrestricted use, distribution, and reproduction in any medium, provided you give appropriate credit to the original author(s) and the source, provide a link to the Creative Commons license, and indicate if changes were made. 


\section{References}

Abrahamse W, Steg L, Vlek C, Rothengatter T (2005) A review of intervention studies aimed at household energy conservation. J Environ Psychol 25:273-291

Adell E, Várhelyi A, Hjälmdahl M (2008) Auditory and haptic systems for in-car speed management-a comparative real life study. Transp Res F Traffic Psychol Behav 11:445-458

af Wåhlberg AE (2007) Long-term effects of training in economical driving: fuel consumption, accidents, driver acceleration behavior and technical feedback. Int J Ind Ergon 37:333-343

Ajzen I (1991) The theory of planned behavior. Organ Behav Hum Decis Process 50:179-211

Barkenbus JN (2010) Eco-driving: an overlooked climate change initiative. Energy Policy 38:762-769

Barwise J, Perry J (1981) Situations and attitudes. J Philos 78:668-691

Beusen B, Broekx S, Denys T, Beckx C, Degraeuwe B, Gijsbers M, Scheepers K, Govaerts L, Torfs R, Panis LI (2009) Using onboard logging devices to study the longer-term impact of an ecodriving course. Transp Res D Transp Environ 14:514-520

Birrell SA, Young MS (2011) The impact of smart driving aids on driving performance and driver distraction. Transp Res F Traffic Psychol Behav 14:484-493

Birrell SA, Young MS, Weldon AM (2010) Delivering smart driving feedback through a haptic pedal. In: Martin Anderson FIEHF, EAC (ed) Proceedings of the international conference on contemporary ergonomics and human factors 2010. Taylor \& Francis, Keele, UK

Birrell SA, Fowkes M, Jennings PA (2014) Effect of using an in-vehicle smart driving aid on real-world driver performance. IEEE Trans Intell Transp Syst 15:1801-1810

Boer ER, Hoedemaeker M (1998) Modeling driver behavior with different degrees of automation: a hierarchical decision framework of interacting mental models. In: Conference on human decision making and manual control. Valenciennes

Brewer PR, Graf J, Willnat L (2003) Priming or framing: media influence on attitudes toward foreign countries. Gazette 65:493-508

Brodje A, Lundh M, Jenvald J, Dahlman J (2013) Exploring non-technical miscommunication in vessel traffic service operation. Cogn Technol Work 15:347-357

Carsten O, Vanderhaegen F (2015) Situation awareness: valid or fallacious? Cogn Technol Work 17:157-158

Chapman P, Underwood G, Roberts K (2002) Visual search patterns in trained and untrained novice drivers. Transp Res F Traffic Psychol Behav 5:157-167

Christie I, Jarvis L (2001) How green are our values? In: Park A, Curtice J, Thomson K, Jarvis L, Bromley C (eds) British social attitudes: the 18th report. London

Cloke J, Harris G, Latham S, Quimby A, Smith L, Baughan C (1999) Reducing the environmental impact of driving: a review of training and in-vehicle technologies. TRL REPORT 384. Berkshire

Cole-Lewis H, Kershaw T (2010) Text messaging as a tool for behavior change in disease prevention and management. Epidemiol Rev 32:56-69

de Groot S, de Winter JCF, García JML, Mulder M, Wieringa PA (2011) The effect of concurrent bandwidth feedback on learning the lane-keeping task in a driving simulator. Hum Factors 53:50-62

Delhomme P, Cristea M, Paran F (2013) Self-reported frequency and perceived difficulty of adopting eco-friendly driving behavior according to gender, age, and environmental concern. Transp Res D Transp Environ 20:55-58

Delicado A (2012) Environmental education technologies in a social void: the case of 'Greendrive'. Environ Educ Res 18:831-843
Dogan E, Steg L, Delhomme P (2011) The influence of multiple goals on driving behavior: the case of safety, time saving, and fuel saving. Accid Anal Prev 43:1635-1643

Dogan E, Bolderdijk JW, Steg L (2014) Making small numbers count: environmental and financial feedback in promoting eco-driving behaviours. J Consum Policy 37:413-422

Engström J, Johansson E, Östlund J (2005) Effects of visual and cognitive load in real and simulated motorway driving. Transp Res F Traffic Psychol Behav 8:97-120

Fischer C (2008) Feedback on household electricity consumption: a tool for saving energy? Energ Effic 1:79-104

Fiske ST, Taylor SE (1984) Social cognition. Addison-Wesley, Reading

Fiske ST, Taylor SE (2013) Social cognition: from brains to culture. Sage, London

Garnham A (1997) Representing information in mental models. In: Conway MA (ed) Cognitive models of memory. MIT Press, Cambridge

Gawronski B, Bodenhausen GV (2006) Associative and propositional processes in evaluation: an integrative review of implicit and explicit attitude change. Psychol Bull 132:692-731

Geller ES, Wylie RG, Farris JC (1971) An attempt at applying prompting and reinforcement toward pollution control. In: American psychological association meeting 79th annual convention. Washington, DC

Greenwald AG (2014) Why attitudes are important: defining attitude. In: Pratkanis AR, Breckler SJ, Greenwald AG (eds) Attitude structure and function. Erlbaum, Hillsdale

Harvey J, Thorpe N, Fairchild R (2013) Attitudes towards and perceptions of eco-driving and the role of feedback systems. Ergonomics 56:507-521

Herr PM (1986) Consequences of priming: judgment and behavior. J Pers Soc Psychol 51:1106-1115

Herr PM, Sherman SJ, Fazio RH (1983) On the consequences of priming: assimilation and contrast effects. J Exp Soc Psychol 19:323-340

Hibberd DL, Jamson H, Jamson SL (2015) The design of an invehicle assistance system to support eco-driving. Transp Res C Emerg Technol 58:732-748

Hiraoka T, Nishikawa S, Yamabe S, Matsumoto S (2010) Sustainability verification of eco-driving behavior based on driving simulator experiments. In: Proceedings of 17 th world congress on intelligent transport systems

Hutchins E (1995) Cognition in the wild. Massachusetts, The MIT Press, Cambridge

Hutchins EL, Hollan JD, Norman DA (1985) Direct manipulation interfaces. Hum Comput Interact 1:311-338

Iyengar S, Kinder DR (1987) News that matters: television and American opinion. The University of Chicago Press, Chicago

Jackson T (2005) Motivating sustainable consumption. A review of evidence on consumer behaviour and behavioural change. A report to the Sustainable Development Research Network, Surrey: Centre for Environmental Strategies. Guildford, Surrey

Jamson AH, Hibberd DL, Merat N (2015a) Interface design considerations for an in-vehicle eco-driving assistance system. Transp Res C Emerg Technol 58(Part D):642-656

Jamson SL, Hibberd DL, Jamson AH (2015b) Drivers' ability to learn eco-driving skills; effects on fuel efficient and safe driving behaviour. Transp Res C Emerg Technol 58(Part D):657-668

Johansson H, Färnlund J, Engström C (1999) Impact of EcoDriving on emissions and fuel consumption: a pre-study. Swedish National Road Administration Report Borlange, Sweden

Johnson-Laird PN (1983) Mental models: towards a cognitive science of language, inference, and consciousness. UK, Cambridge University Press, Cambridge 
Large DR, Burnett GE (2014) The effect of different navigation voices on trust and attention while using in-vehicle navigation systems. J Saf Res 49:69-75

Latinus M, Belin P (2011) Human voice perception. Curr Biol 21:R143-R145

Martens MH, Fox MRJ (2007) Do familiarity and expectations change perception? Drivers' glances and response to changes. Transp Res F Traffic Psychol Behav 10:476-492

Martin LL (1986) Set/reset: use and disuse of concepts in impression formation. J Pers Soc Psychol 51:493-504

McIlroy RC, Stanton NA (2014) Climbing decision ladders to analyse ecodriving: the first rung on the way to fuel-efficient driving. In: Ahram T, Karwowski W, Marek T (eds) 5th international conference on applied human factors and ergonomics AHFE. Krakow, Poland

McIlroy RC, Stanton NA (2017) What do people know about ecodriving? Ergonomics 60:754-769

Mensing F, Bideaux E, Trigui R, Tattegrain H (2013) Trajectory optimization for eco-driving taking into account traffic constraints. Transp Res D Transp Environ 18:55-61

Mensing F, Bideaux E, Trigui R, Ribet J, Jeanneret B (2014) Ecodriving: an economic or ecologic driving style? Transp Res $\mathrm{C}$ Emerg Technol 38:110-121

Meschtscherjakov A, Wilfinger D, Scherndl T, Tscheligi M (2009) Acceptance of future persuasive in-car interfaces towards a more economic driving behaviour. In: Proceedings of the $1 \mathrm{st}$ international conference on automotive user interfaces and interactive vehicular applications (Automotive UI). Essen, Germany: ACM

Michon JA (1985) A critical view of driver behavior models: what do we know, what should we do. In: Evans L, Schwing RC (eds) Human behavior and traffic safety. Plenum, New York

Newell A (1973) Productions systems: models of control structures. In: Chase WG (ed) Visual information processing. Academic Press, New York

Pampel SM, Jamson S, Hibberd D, Barnard Y (2015) How I reduce fuel consumption: an experimental study on mental models of eco-driving. Transp Res C Emerg Technol 58:669-680

Putnam H (1975) Is semantics possible? In: Putnam H (ed) Mind, language and reality. Philosophical papers. Cambridge University Press, Cambridge

Rasmussen J (1979) Notes on human error analysis and prediction. In: Apostolakis G, Volta G (eds) Synthesis and analysis methods for safety and reliability studies. Plenum Press, London

Rasmussen J (1983) Skills, rules, and knowledge; signals, signs, and symbols, and other distinctions in human performance models. In: IEEE transactions on systems, man and cybernetics, SMC-13, pp 257-266

Rexeis M, Hausberger S, Riemersma I, Tartakovsky L, Zvirin Y, Cornelis E (2005) Heavy-duty vehicle emissions. Final report of WP 400. ARTEMIS (Assessment and reliability of transport emission models and inventory systems); DGTREN Contract 1999-RD.10429

Rimini-Döring M, Keinath A, Nodari E, Palma F, Toffetti A, Floudas N, Bekiaris E, Portouli V, Panou M (2005) Considerations on test scenarios. AIDE Deliv 2(1):3

Risto M, Martens MH (2013) Factors influencing compliance to tactical driver advice: an assessment using a think-aloud protocol. In: 2013 16th International IEEE conference on intelligent transportation systems - (ITSC). The Hague, IEEE

Rolim C, Baptista P, Duarte G, Farias T, Pereira J (2016) Impacts of delayed feedback on eco-driving behavior and resulting environmental performance changes. Transp Res Part F Traffic Psychol Behav 43:366-378

Roskos-Ewoldsen DR, Roskos-Ewoldsen B, Carpentier FRD (2002) Media priming: a synthesis. In: Bryant J, Zillmann D (eds) Media effects: advances in theory and research. Lawrence Erlbaum Associates, Hillsdale

Rumelhart DE (1980) Schemata: the building blocks of cognition. In: Spiro RJ, Bruce BC, Brewer WF (eds) Theoretical issues in reading comprehension: perspectives from cognitive psychology, linguistics, artificial intelligence, and education. Erlbaum, Hillsdale

Samaras Z, Ntziachristos L (1998) Average hot emission factors for passenger cars and light duty trucks. Methodologies for estimating air pollutant emissions from transport (MEET)—Deliverable 7. Thessaloniki, Greece: Lab. of Applied Thermodynamics, Aristotle University of Thessaloniki

Sarason IG, Minard J (1962) Test anxiety, experimental instructions, and the Wechsler Adult Intelligence Scale. J Educ Psychol 53:299-302

Schall DL, Wolf M, Mohnen A (2016) Do effects of theoretical training and rewards for energy-efficient behavior persist over time and interact? A natural field experiment on eco-driving in a company fleet. Energy Policy 97:291-300

Seligman C, Becker LJ, Darley JM (1981) Encouraging residential energy conservation through feedback. In: Baum A, Singer JE (eds) Advances in environmental psychology. Lawrence Erlbaum Associates, Hillsdale

Sharples S, Shalloe S, Burnett G, Crundall D (2015) Journey decision making: the influence on drivers of dynamic information presented on variable message signs. Cognit Technol Work 18:1-153

Siero S, Boon M, Kok G, Siero F (1989) Modification of driving behavior in a large transport organization: a field experiment. J Appl Psychol 74:417-423

Stockwell MS, Westhoff C, Kharbanda EO, Vargas CY, Camargo S, Vawdrey DK, Castaño PM (2013) Influenza vaccine text message reminders for urban, low-income pregnant women: a randomized controlled trial. Am J Public Health 104:e7-e12

Stunkel L, Grady C (2011) More than the money: a review of the literature examining healthy volunteer motivations. Contemp Clin Trials 32:342-352

Tarkiainen M, Peltola H, Koskinen S, Schirokoff A (2014) Trafisafefeedback for novice drivers. 10th ITS European Congress. Helsinki

Taylor M, Lynam D, Baruya A (2000) The effects of drivers' speed on the frequency of road accidents. TRL Report 421. Transport Research Laboratory Crowthorne, Berkshire

Trick LM, Enns JT (2009) A two-dimensional framework for understanding the role of attentional selection in driving. In: Castro $\mathrm{C}$ (ed) Human factors of visual and cognitive performance in driving. CRC Press, Boca Raton

University of Leeds (2013) University of Leeds Driving Simulator (UoLDS) [Online]. University of Leeds, Leeds. http://www.uolds. leeds.ac.uk/. Accessed 16 Sep 2013

Vallacher RR, Wegner DM (1987) What do people think they're doing? Action identification and human behavior. Psychol Rev 94:3-15

van der Voort M, Dougherty MS, van Maarseveen M (2001) A prototype fuel-efficiency support tool. Transp Res C Emerg Technol 9:279-296

van Erp JBF, van Veen HAHC (2004) Vibrotactile in-vehicle navigation system. Transp Res F Traffic Psychol Behav 7:247-256

Waters MHL, Laker IB (1980) Research on fuel conservation for cars. Transport and Road Research Laboratory, Crowthorne

Wilson M (2002) Six views of embodied cognition. Psychon Bull Rev 9:625-636

Wyer RS Jr, Radvansky GA (1999) The comprehension and validation of social information. Psychol Rev 106:89-118

Zwaan RA, Radvansky GA (1998) Situation models in language comprehension and memory. Psychol Bull 123:162-185 